\title{
Time-dependent rheological characteristics of self-consolidating concrete containing various mineral admixtures
}

\author{
Reza Saleh Ahari ${ }^{\mathrm{a}, *}$, Tahir Kemal Erdem ${ }^{\mathrm{b}}$, Kambiz Ramyar ${ }^{\mathrm{c}}$ \\ a Department of Civil Engineering, Tabriz Branch, Islamic Azad University, Tabriz, Iran \\ ${ }^{\mathrm{b}}$ Department of Civil Engineering, Izmir Institute of Technology, Izmir, Turkey \\ ${ }^{\mathrm{c}}$ Department of Civil Engineering, Ege University, Izmir, Turkey
}

\section{H I G H L I G H T S}

- Time-dependent rheology of SCC with various mineral admixtures was investigated.

- Apparent yield stress and thixotropy of SCC increased significantly with time.

- Time-dependent torque plastic viscosity values changed only in a limited range.

- Viscosity and yield stress were affected mostly by metakaolin and Class C fly ash.

- Metakaolin and silica fume, had more influence on thixotropy as time was elapsed.

\section{A R T I C L E I N F O}

\section{Article history:}

Received 5 January 2015

Received in revised form 11 March 2015

Accepted 7 April 2015

Available online 24 April 2015

\section{Keywords:}

Self-consolidating concrete

Mineral admixture

Elapsing time

Plastic viscosity

Thixotropy

\begin{abstract}
A B S T R A C T
The study herein was intended to evaluate the influence of elapsing time on rheological properties and thixotropy of self-consolidating concrete (SCC) mixtures containing various mineral admixtures. For this purpose, variation of $T_{50}$ flow time, torque plastic viscosity, apparent yield stress and thixotropy were investigated as a function of time in a standstill condition. Various amounts of silica fume (SF), metakaolin (MK), Class F fly ash (FAF), Class C fly ash (FAC) and granulated blast-furnace slag (BFS) were utilized in binary, ternary and quaternary cementitious blends in 17 different SCC mixtures having a constant slump flow value. The results showed that SCC mixtures containing various mineral admixtures were highly stable or moderately stable (VSI between 0 and 1 ) at 0 min according to ASTM C 1611 . However, mixtures containing FAC, FAF and BFS exhibited some bleeding and segregation at $50 \mathrm{~min}$. In a standstill condition, apparent yield stress and thixotropy increased significantly with time while torque plastic viscosity values changed only in a limited range. In addition, with elapsing time, MK and FAC were found to have more influence on torque plastic viscosity and yield stress values in comparison with the other admixtures. However, increase in the yield values were more pronounced in comparison with the torque plastic viscosity values. Increase in thixotropy with time for the SF and MK blended mixtures were higher when compared to the control mixtures and mixtures containing the other mineral admixtures.
\end{abstract}

(C) 2015 Elsevier Ltd. All rights reserved.

\section{Introduction}

Rheology and thixotropy of self-consolidating concrete (SCC) have been recognized as important tools to be tailored to achieve a multifold set of engineering properties required for successful accomplishment and performance of the intended application. Static stability, flowability, segregation resistance, formwork

\footnotetext{
* Corresponding author. Tel.: +98 413339 6122; fax: +98 4133317146.

E-mail addresses: rsalehahari@iaut.ac.ir, rsalehahari@mail.ege.edu.tr (R. Saleh Ahari).
}

pressure and its decay after casting, air entrapment, surface quality and interlayer bond strength between consecutive concrete layers strongly depend on rheology and thixotropy of SCC [1-9].

In general, immediately after or during its mixing, concrete is transported from its mixing location to the final destination. Loss of consistency in fresh concrete with elapsing time due to chemical and physical processes (evaporation of water or hydration of cement), segregation and bleeding owing to prolong mixing time, distinct concrete layers arisen from delayed casting between consecutive layers are important problems that are related with rheological properties of flowable concrete. Such problems are 
mostly confronted in the ready-mixed concrete production due to the long travel distances, traffic jamming and delays associated with placement and subsequent operations at the job site. In spite of these difficulties, rheological properties of SCC should remain within acceptable tolerances to achieve a given apparent viscosity and thixotropy for various requirements including pumping pressure and distance, freefall of concrete into formwork, formwork pressure, required stability level after placement and consolidation during the dormant period as well as bond strength between consecutive concrete layers [10-12].

A few studies in the literature investigated the rheological properties of cement pastes and concrete having high consistency as a function of time [12-19]. Martini et al. [13] investigated the effect of time on rheological properties of cement pastes with various superplasticizers. It was reported that, regardless of the type of admixture, the thixotropy of mixtures increased with time below the admixture saturation dosage. $\mathrm{Li}$ et al. [14] concluded that the increase in apparent plastic viscosity and yield stress with the elapsed time was more significant when the concrete mixture was under the standstill condition than under continuous agitation. In another investigation Ferron et al. [15] determined the structural buildup of cement pastes of SCC containing silica fume (SF) and fly ash (FA) at a rest time up to $90 \mathrm{~min}$. It was reported that in a standstill condition structural buildup of SF and FA blended mixtures increased with time. The enhancement was more significant in the mixtures having lower slump flow values compared to the mixtures with high flow properties. Assaad et al. [16] showed that in a standstill condition, thixotropy of SCC mixtures containing SF and FA increased as time was elapsed. They reported that increase in thixotropy was more significant when both SF and FA were incorporated with PC in SCC mixtures in comparison with the mixtures containing only PC. In a more recent study, Lomboy et al. [18] studied the rheological behavior of SCC and normal concrete as a function of time in a standstill condition. It was found that in SCC mixtures yield stress values increased with time while plastic viscosity and thixotropy values did not show a significant change with time.

Utilization of mineral admixtures as cementitious materials in concrete has a tendency to increase in future in order to provide greater sustainability in construction industry. In addition to the enhancement of mechanical properties and durability, the use of mineral admixtures can improve rheological properties and stability of the fresh concretes. Moreover, the use of by-product mineral admixtures can decrease the cost of SCC and the amount of the $\mathrm{CO}_{2}$ emitted during the production of PC. Besides, incorporation of different mineral admixtures in ternary and quaternary binders can have a considerable synergistic effect on both fresh and hardened properties of the concrete. Moreover, utilizing byproducts or wastes as alternative cementitious materials in concrete provides a more sustainable concrete technology through the creation of a balance between development and environment [20-27].

As a part of a more extensive study [2], this paper presents the time-dependent variation of rheological properties of SCC containing various mineral admixtures. It is aimed to develop a better understanding of time-dependent variation of rheology on the performance of SCC in a standstill condition, and to formulate more realistic recommendations for using mineral admixtures in SCC. For this purpose SCC mixtures with $\mathrm{a} w / \mathrm{b}=0.44$ were prepared with various amounts of Class C fly ash (FAC), Class F fly ash (FAF), SF, BFS and MK at a constant slump by adjusting the superplasticizer dosage. The rheological properties of mixtures were evaluated with a coaxial cylinder concrete rheometer after 0 and 50 min of mixing.

\section{Experimental methods}

\subsection{Materials}

In this study an ordinary portland cement (CEM I $42.5 \mathrm{R}$ ) and five types of mineral admixtures, i.e., SF, FAC, FAF, MK, and BFS were used as binary, ternary and quaternary cementitious blends in SCC mixtures. Table 1 and Fig. 1 summarizes the physical and chemical properties and particle-size distributions of the PC and mineral admixtures. In addition, the micrographs of the mineral admixtures and PC demonstrating their shape and texture are shown in Fig. 2. Crushed limestone with a maximum particle size of $15 \mathrm{~mm}$ and $4 \mathrm{~mm}$ were used as coarse and fine aggregate, respectively. The bulk specific gravity and absorption capacity of the coarse and fine aggregates were 2.64 and 2.61 , as well as $0.21 \%$ and $0.67 \%$, respectively. A polycarboxylate ether-based high-range water-reducer (HRWR), conforming to ASTM C494 Type F [28] with a specific gravity of 1.06 and solid content of $28 \%$ was employed to achieve the desired workability.

\subsection{Mix proportions and mixing}

As summarized in Table 2, in addition to the control mixture without any mineral admixture, 16 SCC mixtures containing various types and amounts of mineral admixtures were designed to have a constant w/b ratio of 0.44 and a total binder content of $454.5 \mathrm{~kg} / \mathrm{m}^{3}$. In all of the SCC mixtures the fine aggregate-to-total aggregate ratio, by mass, was set at 0.53 . The HRWR dosages used in the mixtures were adjusted to secure an initial slump flow of $650 \pm 10 \mathrm{~mm}$. By the partial replacement of cement with the mineral admixtures, binary $(\mathrm{PC}+\mathrm{SF}, \mathrm{PC}+\mathrm{FAC}, \mathrm{PC}+\mathrm{FAF}, \mathrm{PC}+\mathrm{MK}$ and $\mathrm{PC}+\mathrm{BFS})$, ternary $(\mathrm{PC}+\mathrm{SF}+\mathrm{BFS}, \quad \mathrm{PC}+\mathrm{FAC}+\mathrm{BFS}, \quad \mathrm{PC}+\mathrm{FAF}+\mathrm{BFS}$ and $\mathrm{PC}+\mathrm{MK}+\mathrm{BFS})$ and quaternary $(\mathrm{PC}+\mathrm{SF}+\mathrm{FAC}+\mathrm{BFS})$ cementitious blends were. The mix proportion of ternary and quaternary mixtures was selected according to the conducting trial tests and those applied by the other researchers. The replacement levels of the various mineral admixtures were different: i.e., $4 \%, 8 \%$ and $12 \%$ for $\mathrm{SF}, 4 \%, 8 \%, 18 \%$ and $36 \%$ for MK, $18 \%$ and $36 \%$ for FA and only $18 \%$ for BFS. All substitutions of the cement by mineral admixtures were made on the total mass basis of the binder. The factors such as mixing efficiency, mixer type, mixing sequence, etc. that affect the properties of SCC during its production $[29,30]$ were kept constant throughout the study. The mixing procedure consisted of homogenizing the aggregate with $35 \%$ of the mixing water for $1 \mathrm{~min}$ in a batch of $20 \mathrm{~L}$ using a rotary planetary mixer. Then, the cementitious materials with $40 \%$ of the mixing water were added and mixed for further 2 min. Afterwards, the HRWR, diluted with the remaining water, was introduced gradually over $2 \mathrm{~min}$. Following $2 \mathrm{~min}$ of rest, the concrete was mixed for 3 additional min. The ambient temperature during mixing and testing was maintained constant at $20 \pm 2{ }^{\circ} \mathrm{C}$. The mixtures are designated according to the type and amount of the cementitious materials. For example, 8SF18FAC18BFS shows the quaternary mixture containing $8 \% \mathrm{SF}, 18 \%$ FAC and $18 \%$ BFS by mass of the cement.

\subsection{Testing procedure}

The measurement of fresh SCC properties was started immediately after mixing ( 9 min after the initial contact of water with cement). The slump flow values were represented by the mean diameter (measured from two perpendicular directions) of the concrete spread after lifting the standard slump cone. The final diameter was determined in the slump flow test, and the time required for the concrete to spread to a diameter of $500 \mathrm{~mm}\left(\mathrm{~T}_{50}\right)$ was recorded. Once a slump flow of $650 \mathrm{~mm}$ was ensured, the visual stability index (VSI) of the mixtures was determined according to ASTM C 1611 [31]. Then, the rheological parameters (torque plastic viscosity and apparent yield stress) were evaluated using a coaxial cylinder concrete rheometer (ConTec 4SCC). A four-bladed vane rotating coaxially was used

Table 1

Physical and chemical properties of PC and mineral admixtures.

\begin{tabular}{|c|c|c|c|c|c|c|}
\hline & PC & SF & FAC & FAF & MK & BFS \\
\hline $\mathrm{CaO}, \%$ & 64.06 & 0.25 & 36.56 & 3.24 & 0.3 & 35.2 \\
\hline $\mathrm{SiO}_{2}, \%$ & 17.74 & 87.92 & 31.94 & 59.5 & 51.1 & 40.3 \\
\hline $\mathrm{Al}_{2} \mathrm{O}_{3}, \%$ & 4.76 & 0.4 & 13.5 & 18.5 & 39.1 & 10.2 \\
\hline $\mathrm{Fe}_{2} \mathrm{O}_{3}, \%$ & 3.17 & 0.35 & 4.09 & 6.96 & 2.15 & 0.67 \\
\hline $\mathrm{MgO}, \%$ & 1.28 & 3.97 & 1.42 & 2.03 & 0.7 & 6.9 \\
\hline $\mathrm{SO}_{3}, \%$ & 2.94 & 0.21 & 3.86 & 0.47 & 0.08 & 1.4 \\
\hline $\mathrm{K}_{2} \mathrm{O}, \%$ & 0.8 & 0.81 & 0.94 & 1.93 & 1.78 & 0.97 \\
\hline $\mathrm{Na}_{2} \mathrm{O}, \%$ & 0.45 & 1.79 & 1.1 & 1.27 & 0.11 & 1.12 \\
\hline Free lime, \% & 2.21 & - & 2.69 & 0.42 & - & - \\
\hline Other minor oxides, \% & 0.64 & 1.43 & 0.91 & 1.26 & 0.88 & 1.34 \\
\hline Loss on ignition, $\%$ & 1.95 & 2.87 & 2.99 & 4.32 & 3.8 & 1.9 \\
\hline Specific gravity & 3.13 & 2.29 & 2.73 & 2.38 & 2.54 & 2.97 \\
\hline Blaine fineness, $\mathrm{cm}^{2} / \mathrm{g}$ & 3310 & - & 3470 & 3220 & - & 3650 \\
\hline Surface area B.E.T., $\mathrm{m}^{2} / \mathrm{kg}$ & - & 24,520 & - & - & 15,410 & - \\
\hline Residue on $45 \mu \mathrm{m}$ sieve, \% & 4.2 & - & 17.4 & 19.5 & 0.4 & 1.3 \\
\hline
\end{tabular}




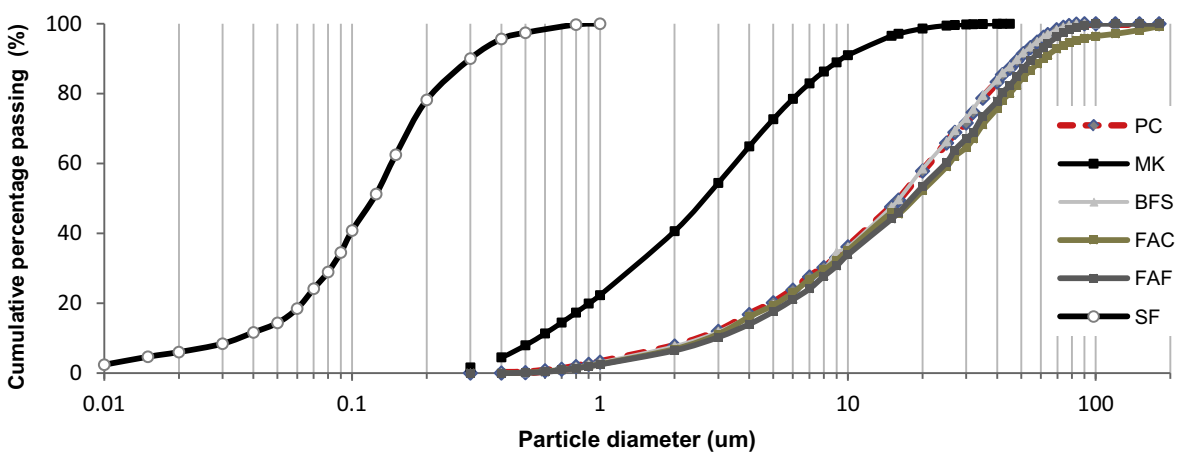

Fig. 1. Particle size distributions of $P C$ and mineral admixtures.

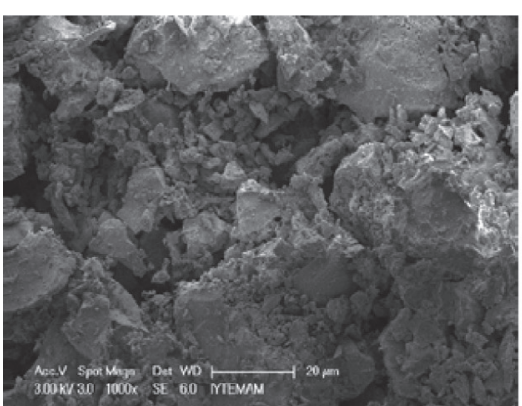

(a)

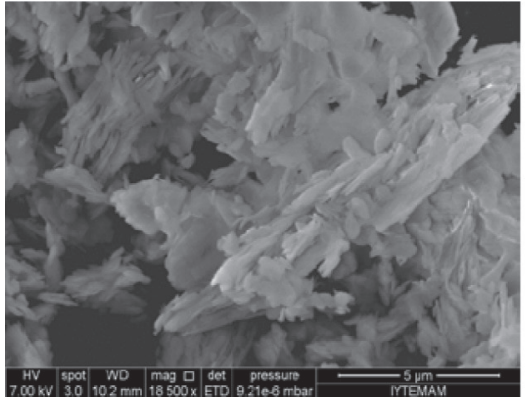

(d)

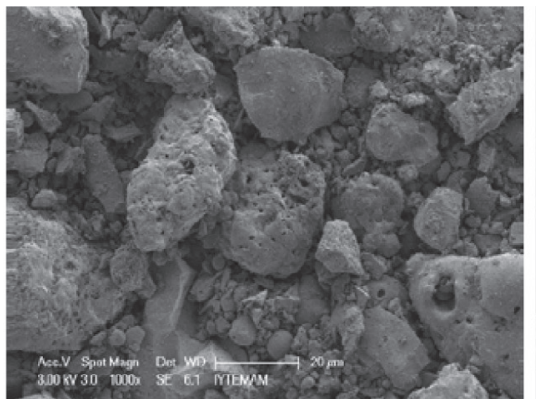

(b)

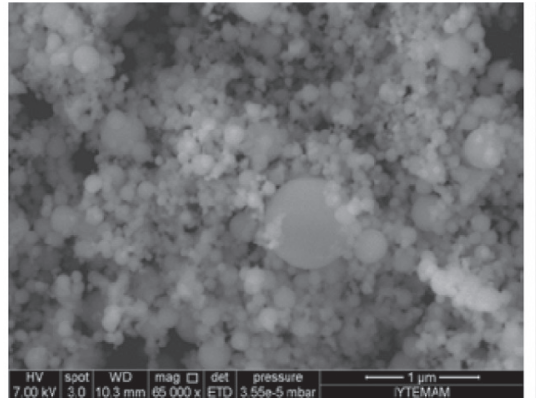

(e)

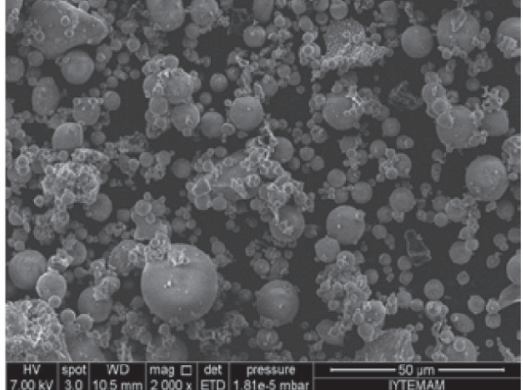

(c)

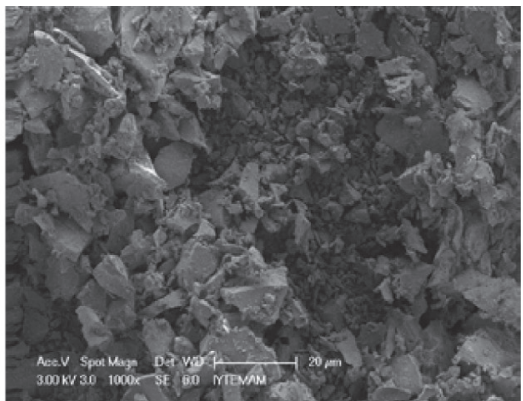

(f)

Fig. 2. SEM images of (a) PC, (b) FAC, (c) FAF, (d) MK, (e) SF and (f) BFS particles.

Table 2

Mix proportions of SCC mixtures substituted with mineral admixtures $\left(\mathrm{kg} / \mathrm{m}^{3}\right)$.

\begin{tabular}{|c|c|c|c|c|c|c|c|c|c|c|}
\hline \multirow[t]{2}{*}{ Mixture ID } & \multirow[t]{2}{*}{ Water } & \multirow[t]{2}{*}{ PC } & \multirow[t]{2}{*}{ SF } & \multirow[t]{2}{*}{ FAC } & \multirow[t]{2}{*}{ FAF } & \multirow[t]{2}{*}{ MK } & \multirow[t]{2}{*}{ BFS } & \multirow[t]{2}{*}{ HRWR } & \multicolumn{2}{|c|}{ Aggregates (SSD) } \\
\hline & & & & & & & & & Fine & Coarse \\
\hline Control & 200 & 454.5 & - & - & - & - & - & 5.75 & 883 & 783 \\
\hline $4 \mathrm{SF}$ & 200 & 436.5 & 18 & - & - & - & - & 6.70 & 880 & 778 \\
\hline $8 \mathrm{SF}$ & 200 & 418.5 & 36 & - & - & - & - & 7.50 & 875 & 774 \\
\hline $12 \mathrm{SF}$ & 200 & 400 & 54.5 & - & - & - & - & 8.0 & 870 & 771 \\
\hline 8SF18BFS & 200 & 337 & 36 & - & - & - & 81.5 & 6.70 & 874 & 774 \\
\hline $18 \mathrm{FAC}$ & 200 & 373 & - & 81.5 & - & - & - & 5.82 & 878 & 778 \\
\hline $36 F A C$ & 200 & 291 & - & 163.5 & - & - & - & 6.35 & 872 & 773 \\
\hline 36FAC18BFS & 200 & 209.5 & - & 163.5 & - & - & 81.5 & 5.50 & 871 & 772 \\
\hline 18FAF & 200 & 373 & - & - & 81.5 & - & - & 4.67 & 872 & 772 \\
\hline $36 \mathrm{FAF}$ & 200 & 291 & - & - & 163.5 & - & - & 4.36 & 859 & 762 \\
\hline 36FAF18BFS & 200 & 209.5 & - & - & 163.5 & - & 81.5 & 4.31 & 858 & 761 \\
\hline $8 \mathrm{MK}$ & 200 & 418.5 & - & - & - & 36 & - & 6.50 & 878 & 779 \\
\hline $18 \mathrm{MK}$ & 200 & 373 & - & - & - & 81.5 & - & 7.50 & 873 & 773 \\
\hline $36 \mathrm{MK}$ & 200 & 291 & - & - & - & 163.5 & - & 10.0 & 861 & 762 \\
\hline 36MK18BFS & 200 & 209.5 & - & - & - & 163.5 & 81.5 & 9.35 & 860 & 761 \\
\hline 18BFS & 200 & 373 & - & - & - & - & 81.5 & 5.35 & 881 & 781 \\
\hline 8SF18FAC18BFS & 200 & 255.5 & 36 & 81.5 & - & - & 81.5 & 7.0 & 868 & 769 \\
\hline
\end{tabular}


for the impeller. The container of the rheometer had an internal diameter of $240 \mathrm{~mm}$ and a depth of $240 \mathrm{~mm}$, allowing a concrete sample volume of approximately 8 L. Following the rheology tests, thixotropy tests were performed. In order to determine the effect of elapsing time, the rheological parameters were measured at 0 and $50 \mathrm{~min}$ after mixing. To prevent the effect of evaporation, the fresh mixtures was covered by plastic sheets during standstill time interval. At the end of 50 min rest, the concrete was remixed for 2 min and the measurements of the fresh properties were repeated. The 28-day compressive strength of the mixtures was also determined according to ASTM C 39 [32]. The average compressive strength of three specimens was recorded for each mixture.

\subsubsection{Evaluating torque plastic viscosity and apparent yield stress}

Torque plastic viscosity of the mixtures was measured at five different revolution speeds of $0.70,0.55,0.40,0.25$ and 0.10 rps. The selected speed values were determined by conducting trial tests and are similar to those applied by the other researchers [16,33]. The measuring sequence started from the highest speed to the slowest speed (down-curve). Each speed was applied for a period of $8 \mathrm{~s}$. However, the torque values obtained only during the last $6 \mathrm{~s}$ of the test were used in calculating the average torque value corresponding to that speed. Since it was possible to take 4 torque readings per second from the rheometer, $6 \times 4=24$ torque values were averaged for each speed. In this way, torque-rotation speed chart was generated for each concrete mixture. Bingham model was constructed by fitting the best line to the data. The intersection point of the trendline with the torque axis (apparent yield stress, $g$ ) and the slope of the trendline (torque plastic viscosity, h) were determined.

\subsubsection{Evaluating thixotropy by breakdown area}

Structural breakdown values of the mixtures were evaluated by the approach recommended by Lapasin et al. [34]. In this method, after five minutes of rest in the bowl of the rheometer, the mixture was subjected to a constant rotational speed of $0.2 \mathrm{rps}$ for $10 \mathrm{~s}$. Then, after another five-minute rest period, the mixture was subjected to a constant rotational speed of $0.4 \mathrm{rps}$ for $10 \mathrm{~s}$. The same procedure was repeated for speeds of 0.6 and 0.8 rps. For each speed, the time-dependent change in torque was recorded to obtain the initial torque $\left(T_{\mathrm{i}}\right)$ and equilibrium torque $\left(T_{\mathrm{e}}\right)$ values (Fig. 3a). Then, the initial and equilibrium torque values were plotted on torque-rotational speed graphs (Fig. 3b). The best curves, i.e., second order polynomial functions were fitted to the data (Fig. 3b). The area between the initial torque curve and the equilibrium curve, called "structural breakdown area", was calculated by integration and used to quantify the thixotropic behavior of the mixture.

\section{Results and discussion}

\subsection{Visual stability index (VSI)}

The VSI is a method for determining the segregation resistance of the mixture and to evaluate the relative stability of batches of the same SCC mixture. The VSI is determined through visual rating of the concrete appearance just after the slump flow test. The SCC mixture is considered stable and suitable for the intended use when the VSI rating is 0 or 1 , and a VSI rating of 2 or 3 gives an indication of segregation potential [35]. ASTM C1611 [32] defines the VSI value as follows: VSI $(0)=$ concrete mass is homogeneous and no evidence of bleeding, VSI $(1)=$ concrete shows slight bleeding observed as a sheen on the surface, VSI (2)= evidence of a mortar halo and water sheen, VSI (3)= concentration of coarse aggregate at the center of concrete mass and presence of a mortar halo. The VSI values of the 17 SCC mixtures immediately after mixing and when subjected to $50 \mathrm{~min}$. rest are presented in Table 3 . The instability of mixtures were judged by the evidence of mortar halo or bleed water at the edge of the mixture subjected to flow test. At 0 min. the VSI values of most of the mixtures were 0 or 1 indicating their high or moderate stability, respectively. Among the mixtures those containing SF, MK, 18\% FAF, 18\% FAC and the quaternary mixture showed no evidence of segregation or bleeding $(\mathrm{VSI}=0)$. On the other hand, there was a slight bleeding in 36FAC, 18BFS, 8SF18BFS, 36FAC18BFS and 36 FAF mixtures (VS $=1$ ). Besides, some bleeding and segregation was observed in the ternary systems containing BFS and FAF. On the other hand, after 50 min. rest except for 36 FAF18BFS mixture, some reduction in the stability of mixtures was occured. As a result VSI values of the mixtures varied between 0 and 2 . In general, it was found that the presence of BFS in the binder of the mixture increased its liability to the bleeding or segregation.

As shown in Table 3, the VSI values of mixtures containing FAC, FAF and BFS increased after $50 \mathrm{~min}$. of rest. These mixtures exhibited slight bleeding or segregation in slump flow test conducted after a standstill condition of $50 \mathrm{~min}$. The fact was more pronounced in the 36FAF18BFS mixture. The spherical shape and (relatively) smooth texture of FAF particles (Fig. 2c) encouraged their ball-bearing effect to reduce the internal friction between the solid particles in the mixture. This facilitated the settling down of the coarse aggregate particles as well as rising some of the mixing water to the surface of the mixture [19]. The high stability of FAC bearing mixtures was attributed to the angular shape and rough texture of this mineral admixture (Fig. 2b). In addition to increasing the internal friction such particles may absorb some of the mixing water leaving less free water for bleeding. However, the absorption of some of the mixing water and HRWR admixture during the rest period increased the segregation liability of FAC bearing mixtures slightly. Moreover, the low absorption potential of BFS particles arisen from their glassy nature and smooth surface texture (Fig. 2f) seems to be responsible for the high bleeding capacity of the BFS-containing mixtures [2]. The effect was more pronounced after $50 \mathrm{~min}$. rest. Besides, high cohesiveness of the binders containing either SF or MK caused an excellent stability in these mixtures even after $50 \mathrm{~min}$. Rest. This is due to the extremely high surface area of these admixtures $[1,19,36]$.

\section{2. $T_{50}$ flow time}

The $\mathrm{T}_{50}$ flow time of the mixtures after 0 and $50 \mathrm{~min}$. of mixing are presented in Table 3 and Fig. 4. Once again, the high cohesiveness of MK bearing mixtures seems to be the reason for the high $\mathrm{T}_{50}$ flow time of these mixtures at 0 and $50 \mathrm{~min}$. rest times. Owing to the rough texture and high microporosity of FAC particles (Fig. 2 b), similar $T_{50}$ flow time results were obtained in FAC containing mixtures. On the other hand, short $T_{50}$ flow times were recorded in SF and BFS incorporated mixtures irrespective of the

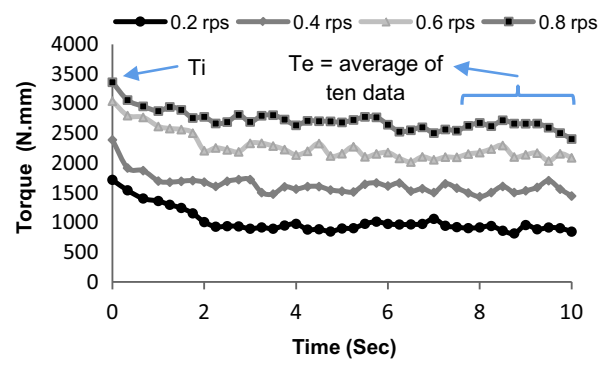

(a)

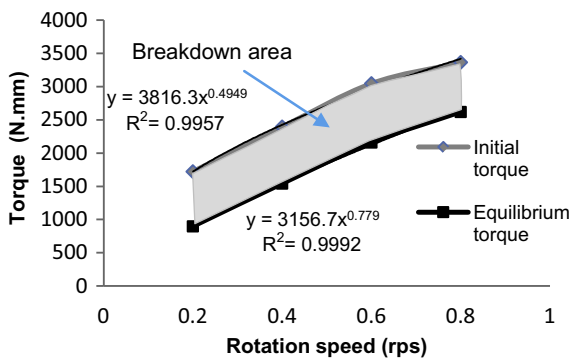

(b)

Fig. 3. Determination of thixotropy by breakdown area method for the 36FAF mixture (a) breakdown curves, (b) structural break-down area calculation. 
Table 3

Properties of the SCC mixtures made with various mineral admixtures.

\begin{tabular}{|c|c|c|c|c|c|c|c|c|c|c|c|}
\hline \multirow[t]{2}{*}{ Mixture ID } & \multirow{2}{*}{$\begin{array}{l}\text { Compressive } \\
\text { strength } \\
(\mathrm{MPa}) \\
28 \text { days }\end{array}$} & \multicolumn{2}{|l|}{ VSI } & \multicolumn{2}{|c|}{$\begin{array}{l}\mathrm{T}_{50} \text { time } \\
(\mathrm{s})\end{array}$} & \multicolumn{2}{|c|}{$\begin{array}{l}\text { Torque plastic } \\
\text { viscosity, (h) } \\
\text { N.mm.s }\end{array}$} & \multicolumn{2}{|c|}{$\begin{array}{l}\text { Apparent yield } \\
\text { stress, (g) } \\
\text { N.mm }\end{array}$} & \multicolumn{2}{|l|}{$\begin{array}{l}\text { Thixotropy } \\
\text { N.mm/s }\end{array}$} \\
\hline & & $0 \mathrm{~min}$ & $50 \mathrm{~min}$ & $0 \mathrm{~min}$ & $50 \mathrm{~min}$ & $0 \mathrm{~min}$ & $50 \mathrm{~min}$ & $0 \mathrm{~min}$ & $50 \mathrm{~min}$ & $0-30 \mathrm{~min}$ & $50-80 \mathrm{~min}$ \\
\hline Control & 43.8 & 0 & 0 & 2 & 4.6 & 1392 & 1522 & 80.0 & 128 & 377 & 463 \\
\hline 4SF & 53.7 & 0 & 0 & 1.6 & 4.1 & 1206 & 1278 & 209 & 307 & 357 & 432 \\
\hline $8 \mathrm{SF}$ & 64 & 0 & 0 & 1.8 & 3.8 & 861 & 957 & 212 & 328 & 391 & 500 \\
\hline $12 \mathrm{SF}$ & 64 & 0 & 0 & 1.1 & 2.8 & 594 & 646 & 280 & 402 & 360 & 471 \\
\hline 8SF18BFS & 66.5 & 1 & 1 & 1.7 & 3 & 700 & 706 & 257 & 330 & 365 & 441 \\
\hline $18 \mathrm{FAC}$ & 50.1 & 0 & 1 & 3.5 & 7.4 & 1826 & 1925 & 88.8 & 190 & 510 & 596 \\
\hline $36 \mathrm{FAC}$ & 56.5 & 1 & 2 & 5.3 & NA & 2626 & 3117 & 116 & 236 & 830 & 962 \\
\hline 36FAC18BFS & 50 & 1 & 2 & 3.8 & 8.1 & 2220 & 2520 & 140 & 287 & 711 & 789 \\
\hline 18FAF & 41 & 0 & 0 & 1.9 & 4.1 & 1476 & 1495 & 129 & 202 & 422 & 493 \\
\hline $36 \mathrm{FAF}$ & 37.6 & 1 & 1 & 2.2 & 4.6 & 1648 & 1662 & 171 & 255 & 508 & 559 \\
\hline 36FAF18BFS & 35.8 & 2 & 3 & 2 & 4.1 & 1512 & 1499 & 216 & 352 & 486 & 524 \\
\hline $8 \mathrm{MK}$ & 45.2 & 0 & 0 & 2.9 & 5 & 1479 & 1553 & 165 & 301 & 449 & 543 \\
\hline $18 \mathrm{MK}$ & 63.4 & 0 & 0 & 3.4 & 6.9 & 1626 & 2000 & 187 & 346 & 487 & 637 \\
\hline $36 \mathrm{MK}$ & 64.5 & 0 & 0 & 4.9 & NA & 2417 & 2663 & 116 & 252 & 837 & 1104 \\
\hline 36MK18BFS & 47.1 & 0 & 1 & 4.1 & NA & 2164 & 2229 & 122 & 243 & 670 & 851 \\
\hline 18BFS & 54.6 & 1 & 1 & 1.9 & 3.1 & 1052 & 1028 & 74.0 & 110 & 337 & 367 \\
\hline 8SF18FAC18BFS & 56.8 & 0 & 0 & 1.5 & 2 & 994 & 982 & 230 & 310 & 472 & 509 \\
\hline
\end{tabular}

Notes: NA: not available.

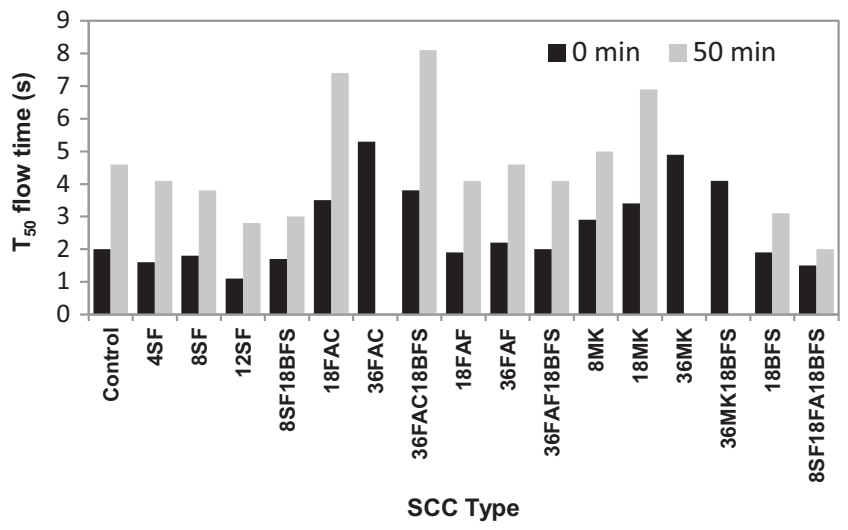

Fig. 4. $T_{50}$ flow times for SCC mixtures for different elapsing times.

rest time duration. Perhaps the ball bearing effect and additional lubrication provided by spherical and smooth-textured SF particles as well as glassy texture of BFS particles are the reasons for this behavior. Besides, partial substitution of PC with either FAF or BFS had a negligible effect on $\mathrm{T}_{50}$ flow time values. Similarly, the mixtures containing ternary binders showed very close $T_{50}$ flow times to those of the counterpart mixtures containing binary binders (without BFS). It should be noted that after $50 \mathrm{~min}$. rest the lowest increase in $\mathrm{T}_{50}$ time was recorded in mixture containing quaternary binder (Fig. 5). On the other hand, the flow values of 35FAC, 36MK and 36MK18BFS mixtures were lower than $500 \mathrm{~mm}$ after $50 \mathrm{~min}$. rest. In short it is possible to claim that the absorption of some of the mixing water and HRWR admixture, controlled by the shape, fineness, surface texture and microporosity of the mineral admixture as well as the rate of hydration of the binder play an important role on the $T_{50}$ flow time of the concrete mixture, particularly after a given rest period.

\subsection{Torque plastic viscosity}

The torque plastic viscosities of the mixtures measured at $0 \mathrm{~min}$. and $50 \mathrm{~min}$. rest times are given in Table 3. The effects of various mineral admixtures on the torque plastic viscosity of freshly mixed SCC immediately after mixing $(0 \mathrm{~min})$ were

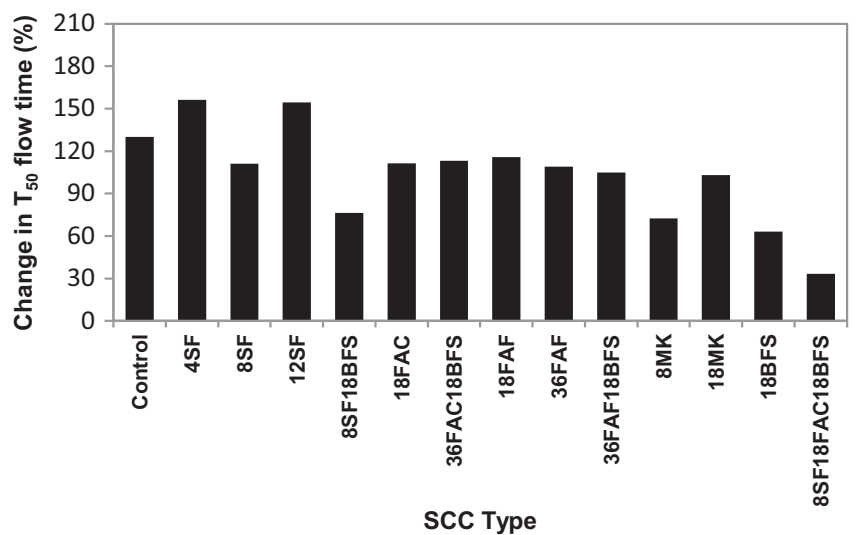

Fig. 5. Change in $\mathrm{T}_{50}$ flow time with time.

discussed elsewhere [2]. The changes in torque plastic viscosity of SCC mixtures upon $50 \mathrm{~min}$. rest were in the range of $-2.3 \%$ to $+23 \%$ as presented in Fig. 6 . By elapsing time a significant increase in the plastic viscosity of MK- and FAC-containing mixtures was found. The highest increase (23\%) was observed in 18MK mixture.

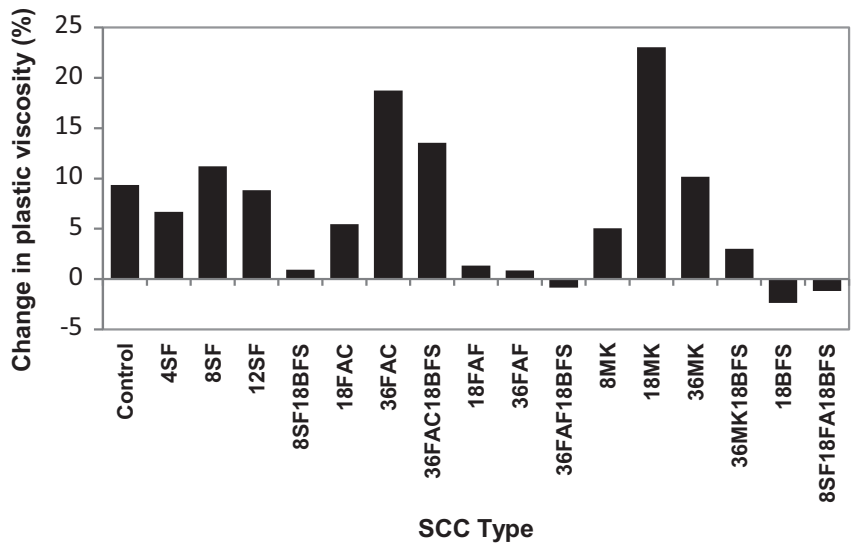

Fig. 6. Change in torque plastic viscosity with time. 
The corresponding value was $18.7 \%$ in 36 FAC mixtures. The cellular structure and high microporosity of MK particles (Fig. 2d) coupled with their high fineness as well as the high microporosity of FAC particles (Fig. 2b) seem to be responsible for the huge change of plastic viscosity in the mixtures containing these admixtures. During the rest period, a considerable amount of mixing water and HRWR are expected to be absorbed by these mineral admixtures. It is well known the absorption of water and HRWR lead to a reduction in inter-particle distance and an increase in the level of attractive forces between solid particles. Both of which may increase the torque plastic viscosity significantly.

As shown in Fig. 6, the change in plastic viscosity of the mixtures incorporating SF (7-11\%), are very close to that of the control mixtures (9\%) containing only PC. The increase in torque plastic viscosity with time in control mixtures can be due to the rapid and progressive hydration of cement resulting in an increase in the solid volume concentration [37]. On the other hand, very fine particles of SF may provide better dispersion of the cement particles and promote their hydration resulting in a slight increase of the plastic viscosity. The effect seems to be masked to some extent by the ballbearing effect of the SF particles which reduce the viscosity through reducing the solid (particularly cement) particles interaction.

On the other hand, except for 36FAC18BFS mixture, those mixtures containing ternary or quaternary binder as well as $18 \mathrm{BFS}$ mixture, the common feature of all of these is the presence of BFS, showed a slight increase or even decrease in torque plastic viscosity after 50 min. rest. Similar results were obtained in FAF bearing mixtures. The fact may be arisen, in part, from lower microporosity and lower absorption and in part, from lower chemical activity of the mineral admixtures during the rest period.

The relationship between $T_{50}$ flow time and torque plastic viscosity for different rest times is plotted in Fig. 7. As can be seen from the figure good correlations $\left(R^{2}=0.865\right.$ and $\left.R^{2}=0.849\right)$ was found between torque plastic viscosity and $\mathrm{T}_{50}$ flow time, irrespective of the duration of rest period. Besides, the slope of the line best fitted to the $0 \mathrm{~min}$. data is somewhat greater than that of the best fitted line to the $50 \mathrm{~min}$. data. This means that at early stages following the mixing, a definite change in the flow time value is an indication of a greater change in torque plastic viscosity, however, the same change in $\mathrm{T}_{50}$ flow time after $50 \mathrm{~min}$. rest corresponds to a smaller change in plastic viscosity. Thus, it may be concluded that any simple empirical value such as $\mathrm{T}_{50}$ flow time is not adequate to fully characterize the fresh concrete under a stand still condition. For this reason it is recommended to use multiple-point based test results for the design and control of the concrete mixtures under standstill conditions.

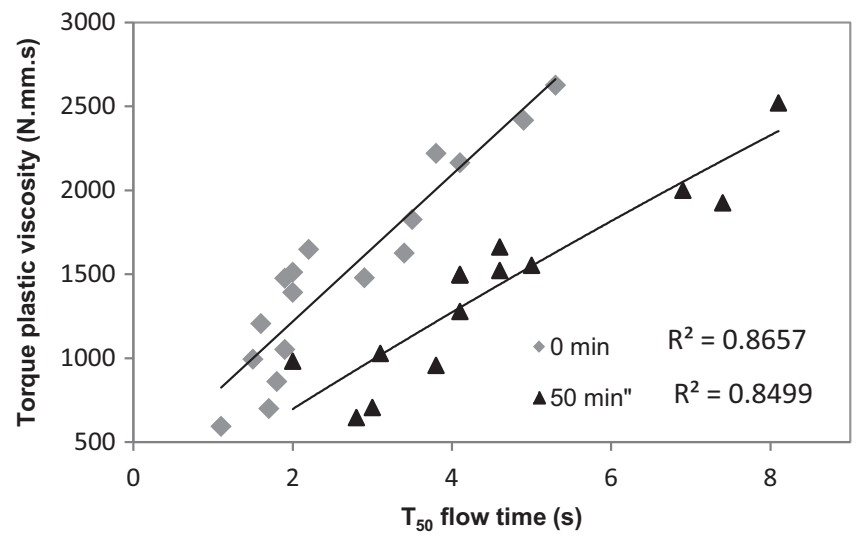

Fig. 7. Relationship between $T_{50}$ flow time and torque plastic viscosity for different elapsing times.

\subsection{Apparent yield stress}

The apparent yield stress values for $0 \mathrm{~min}$ and $50 \mathrm{~min}$ are given in Table 3. The effects of mineral admixtures on the apparent yield stress of freshly mixed SCC with a constant slump flow value were discussed previously [2]. Fig. 8 presents the change in apparent yield stress with time. As it can be seen from the figure, these values range from $28 \%$ to $115 \%$. Similar to the discussions made for torque plastic viscosity, with elapsing time the change (increase) in the yield stress becomes significantly large in MK and FAC blended mixtures. Upon elapsing time, the increase in yield stress values are more pronounced compared to the changes of torque plastic viscosity values. After $50 \mathrm{~min}$. rest, the highest increase in the yield stress (115\%) was observed in 36MK. The corresponding value for $18 \mathrm{FAC}$ mixture was $114 \%$. High surface area and porosity of MK as well as high porosity of FAC particles leave less free water and HRWR with elapsing time. This may lead to a higher degree of friction and provides a greater resistance to the beginning of flow, thereby resulting in an increase of shear stress necessary to maintain a steady-state condition.

In contrast to torque plastic viscosity values (as some reductions were observed in plastic viscosity values), yield stress values increased with time for all SCC mixtures; however, no clear trend were depicted with the replacement level of the mineral admixtures. For instance, apparent yield stress values of 18BFS mixtures was increased $48 \%$ in time while the torque plastic viscosity values for this mixture was decreased by $-2.3 \%$. Similarly, when $36 \mathrm{FAF}$ mixtures had an increase of $49 \%$ in yield values, enhancement of plastic viscosity for this mixture was approximately only $1 \%$ after 50 min of elapsing time. Similar results were observed also by a research of Lomboy et al. [18] where it was found that in a standstill condition, passing of time had significant influence on increase of yield values while similar behavior was not obtained in plastic viscosity values of SCC mixtures. Moreover, similar to our observations, it was observed that yield stress values increased with time while torque plastic viscosity values changed only in a very limited range.

The reason behind this behavior can be summarized as follow: After $50 \mathrm{~min}$ of rest, due to use of free mixing water during the hydration reactions, absorption of water by mineral admixtures, and the decrease in the effect of the HRWR, mixtures become cohesive. When concrete stiffens, the torque values required for initiating the flow (corresponding to yield stress) become higher. But after flow has started, (after the yield stress has been overcome) the flow behavior of concrete is governed by the viscosity. Loss of concrete workability is directly reflected by the increase in yield stress; however, plastic viscosity could show different behavior [38-40].

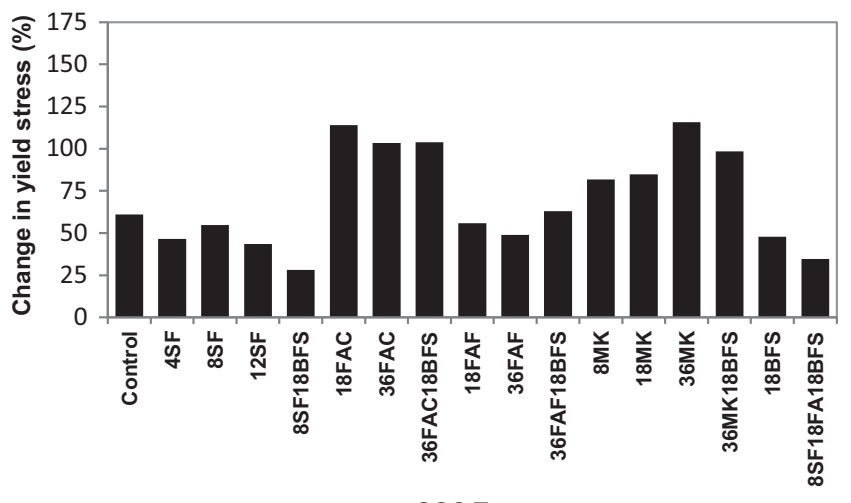

ScC Type

Fig. 8. Change in apparent yield stress with time. 


\subsection{Thixotropy}

Thixotropy is a reversible macroscopic phenomenon and is therefore often associated to reversible physico-chemical phenomena such as flocculation and de-flocculation under shear of colloidal suspensions [41]. It can define the time-dependent behavior of the fluids. In cement-based systems it depends strongly on mixture composition and processing parameters. Utilization of mineral admixtures in concrete increases the internal friction and hence attractive forces among solid particles, which in turn, increase the degree of physical and chemical bonds during cement hydration due to development of structural build-up in the cement based system with time [42-44]. In this study, two rest periods of $0-30$ and $50-80$ min were selected for determining the thixotropy by calculating the structure breakdown area values according to the procedure described in Section 2.3.2. The results are shown in Table 3 and the change in thixotropy with time is presented in Fig. 9. As shown in this figure, these values approximately ranged from $8 \%$ to $32 \%$. Mixtures containing SF and MK had significant influence in enhancement of thixotropy with elapsing time. The highest increase was observed in $36 \mathrm{MK}$ mixture whose thixotropy at $50-80 \mathrm{~min}$ time period was approximately $32 \%$ greater than the thixotropy of the same mixture at 0-30 min. Similarly, 31\% enhancement in thixotropy was observed in mixture containing $12 \% \mathrm{SF}$. On the other hand, the mixtures containing FAC, FAF and BFS had lower rates in enhancement of thixotropy with elapsing time. The lowest rate was observed in 36FAF18BFS mixture that increase was only $7.8 \%$. While the increase in thixotropy of the reference mixture was $23 \%$, it was only $8 \%$ for the quaternary mixture containing $8 \% \mathrm{SF}, 18 \% \mathrm{BFS}$ and $18 \%$ FAC.

A relatively high (23\%) enhancement in thixotropy of the control mixture is related to hydration of PC with time. As a result of PC hydration, concentration of solid particles and interparticle links responsible for flocculation increases with time, causing an increase in thixotropy values. On the other hand, lower rates of enhancement of thixotropy with time for the mixtures containing FAC, FAF and BFS in comparison with control mixtures can be related to the lower degree of hydration of these mixtures. When these mineral admixtures are used with PC, solid volume concentration obtained from hydration of PC and magnitude of restructuring and strength of interparticle links, which have significant effect in thixotropy, can decrease owing to the lower reactivity of these mineral admixtures than PC.

As stated earlier, the increase in thixotropy with time for the SF and MK blended mixtures are higher when compared to the

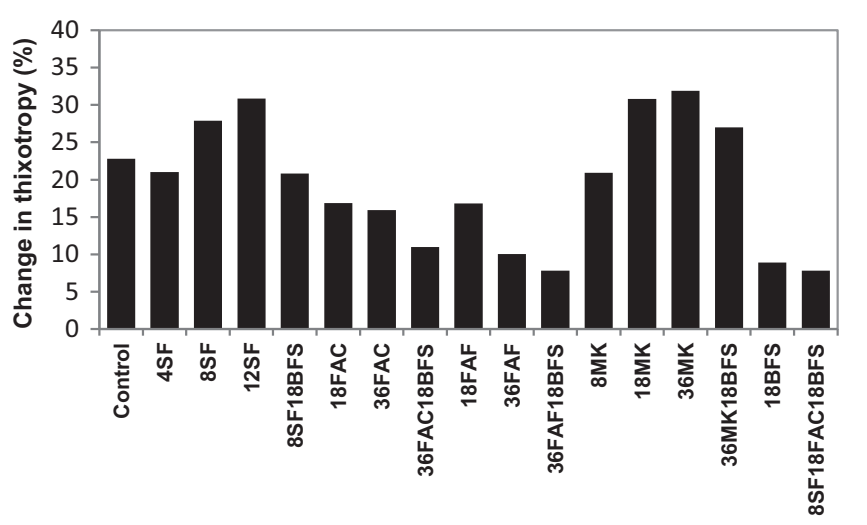

ScC Type

Fig. 9. Change in thixotropy with time. mixtures containing other mineral admixtures and control mixtures. This can be related to the high fineness (Fig. 1 and Table 1) and nucleating effect of these mineral admixtures with time. In a cement-based system, thixotropy is due to colloidal flocculation or CSH bridges between particles. Colloidal flocculation only affects thixotropy on a few seconds time scale and indeed CSH nucleation governs thixotropy behavior. High thixotropy values in the mixtures containing fine mineral admixtures is related to intercalated grains of these fine mineral admixtures with strong nucleating effect [41].

The behavior of the mixtures when left at rest and sheared again can be described as follows: The longer the material is maintained at rest, the more the structural build-up becomes significant, thus requiring higher initial shear stress to break down the structure. This is attributed to the stiffening effect, which enables the material to re-gain its shear strength when left at rest without any shearing action. Once shearing occurs, the particle spatial distribution and alignment become parallel to the flow direction, and the number of entanglements or associations decreases to the minimum. This leads to similar values of shear stress at equilibrium during shearing, thus resulting in higher thixotropy values with time $[33,45]$.

Ferron et al. [15] determined the degree of thixotropy of cement pastes of SCC containing SF at a rest time up to $90 \mathrm{~min}$. Similar to our observation they reported that in a standstill condition structural buildup of SF blended mixtures significantly increased with time. In an another investigation Assaad et al. [16,33] showed that in a standstill condition, thixotropy of SCC mixtures containing SF and FA increased as time was elapsed. They reported that increase in thixotropy was more significant when both SF and FA were incorporated with PC in SCC mixtures in comparison with the mixtures containing only PC.

\subsection{Compressive strength}

Table 3 and Fig. 10 present the 28-day compressive strength of SCC mixtures. Each result is the average of three strength values obtained on $100 \times 200 \mathrm{~mm}$ cylinder specimens. It is clear from Fig. 10 that SF and MK significantly increased the compressive strength. This behavior was due to the high contribution of MK and SF to the strength due to the high pozzolanic activity of their particles at the tested age. As shown in Fig. 10, the highest compressive strength was observed in 8SF18BFS mixture, the compressive strength of which was approximately $52 \%$ greater than of the control mixture. Meanwhile, the lowest compressive strength was found in the 36FAF18BFS mixture. The reduction in the

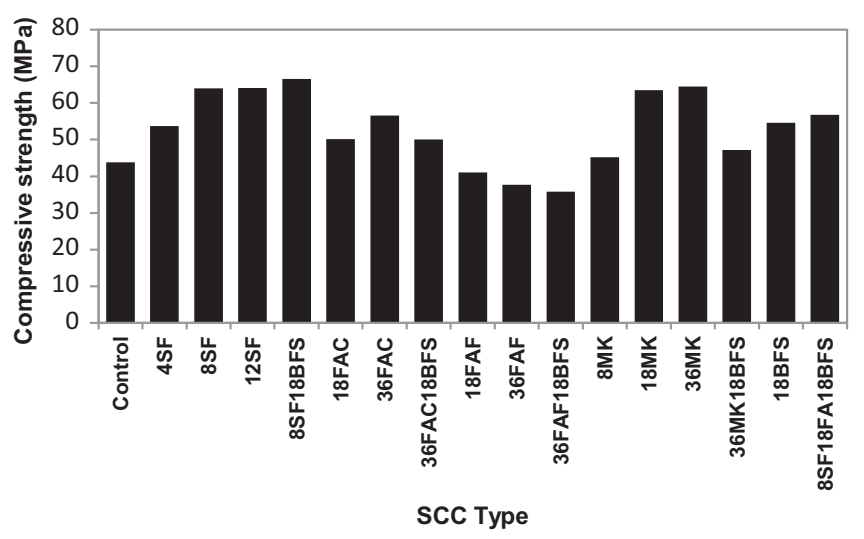

Fig. 10. Variation of compressive strength of SCC mixtures made with various mineral admixtures. 
compressive strength of the concrete upon partial replacement of cement with FAF was more pronounced at higher replacement levels. In contrast to FAF, the compressive strength of FAC mixtures was found to be higher than that of the control mixture. The higher contribution of FAC (than FAF) to the 28-day strength of concrete seems to be arisen from its self cementitious property. As demonstrated in Fig. 10, when BFS was blended with PC and/or SF in the binary or ternary systems, it caused an increase in the compressive strength compared to those of control mixtures. However, when BFS was blended with the other mineral admixtures (i.e., FAF, FAC and MK) it resulted in an opposite effect on the strength of the ternary mixtures. This behavior seems to be due to the amount of the mineral admixture in these mixtures. The mineral admixture content of the ternary binders is $54 \%$ whereas it is $36 \%$ in the counterpart binary binder. On the other hand, the strength development of concretes containing these mineral admixtures and BFS was impaired, indicating the absence of sufficient $\mathrm{CH}$ for BFS pozzolanic activity.

\section{Conclusion}

The rheological properties of an SCC mixture containing a certain type and amount of SCC can be affected by the test methods (such as rheometer type) and material characteristics. Therefore, it should be kept in mind that the following conclusions were derived for the materials used and tests applied in this study:

(1) SCC mixtures containing various mineral admixtures were highly stable and moderately stable (VSI between 0 and 1) at 0 min according to ASTM C 1611. However, mixtures containing FAC, FAF and BFS exhibited some bleeding and segregation at $50 \mathrm{~min}$ while there was no significant change in the stability of SF and MK blended mixtures after 50 min of rest.

(2) $T_{50}$ flow time of almost all mixtures after 50 min of rest (except 18BFS and 8SF18FAC18BFS mixtures) increased approximately 2 times compared to $0 \mathrm{~min}$. MK and FAC were the two mineral admixtures that had most significant effect on $\mathrm{T}_{50}$ with time especially when they were incorporated at high replacement levels.

(3) Mixtures containing MK and FAC, showed significant increase in torque plastic viscosity with time. Torque plastic viscosity of the mixtures incorporating SF displayed comparable behavior to that of the control mixtures with time. Moreover, torque plastic viscosity was reduced in time when BFS was incorporated in binary and quaternary systems. In addition, FAF did not show significant effect on plastic viscosity values as function of time.

(4) Good correlations were established between $T_{50}$ flow time and torque plastic viscosity values, irrespective of the duration of rest period.

(5) In contrast to torque plastic viscosity values, apparent yield stress values increased with time for all SCC mixtures; however, no clear trend was depicted with the replacement level of the mineral admixtures. Similar to torque plastic viscosity values, MK and FAC blended mixtures had significant influence on yield stress with elapsing time. Increase in yield values were more pronounced in comparison with torque plastic viscosity values after 50 min of elapsing time.

(6) Increase in thixotropy with time for the SF and MK blended mixtures were higher when compared to the control mixtures and the mixtures containing other mineral admixtures (FAC, FAF and BFS). The highest increase was observed in 36MK mixture whose thixotropy at 50-80 min time period was approximately $32 \%$ greater than the thixotropy of the same mixture at 0-30 min.
(7) SF and MK significantly increased the compressive strength of the mixtures. The highest compressive strength was observed in 8SF18BFS mixture whose compressive strength was approximately $52 \%$ greater than of the control mixture. The partial replacement of PC by FAF decreased compressive strength of control mixtures while the compressive strength of FAC mixtures was found to be higher than control mixtures.

\section{References}

[1] Saleh Ahari R. Effect of mineral admixtures on rheological, thixotropic and permeability characteristics of self-consolidating concrete (SCC) [Ph.D. thesis], İzmir: Ege University; 2014, 215 p [in Turkish].

[2] Saleh Ahari R, Erdem TK, Ramyar K. Effect of various supplementary cementitious materials on rheological properties of self-consolidating concrete. Constr Build Mater 2015;75:89-98.

[3] Erdem TK, Khayat K, Yahia A. Correlating rheology of self-consolidating concrete to corresponding concrete-equivalent mortar. ACI Mater J 2009;106:154-60.

[4] Assaad J, Khayat KH. Formwork pressure of self consolidating concrete made with various binder types and contents. ACI Mater J 2005;102:215-23.

[5] Khayat KH. Viscosity-enhancing admixtures for cement-based materials - an overview. Cem Concr Compos 1998;20:171-88.

[6] Assaad J, Khayat K, Mesbah H. Variations of formwork pressure with thixotropy of self-consolidating concrete. ACI Mater J 2003;100:29-37.

[7] Roussel N, Cussigh F. Distinct-layer casting of SCC: the mechanical consequences of thixotropy. Cem Concr Res 2008;38:624-32.

[8] Khayat KH, Omran AF, Naji S, Billberg P, Yahia A. Field-oriented test methods to evaluate structural build-up at rest of flowable mortar and concrete. Mater Struc 2012;45:1547-64.

[9] Khayat KH. Optimization and performance of air-entrained, self compacting concrete. ACI Mater J 2000;97:526-35.

[10] Kirca O, Turanli L, Erdogan TY. Effects of retempering on consistency and compressive strength of concrete subjected to prolonged mixing. Cem Concr Res 2002;32:441-5.

[11] Erdogdu S. Effect of retempering with superplasticizer admixtures on slump loss and compressive strength of concrete subjected to prolonged mixing. Cem Concr Res 2005;35:907-12.

[12] Diawara H, Ghafoori N. Influence of hauling time on fresh properties of Selfconsolidating concrete. ACI Mater J 2011;108:244-51.

[13] Martini SAL, Nehdi M. Coupled effects of time and high temperature on rheological properties of cement pastes incorporating various superplasticizers. J Mater Civ Eng ASCE 2009;21:392-401.

[14] Li Z, Ohkubo T, Tanigawa Y. Theoretical analysis of time-dependence and thixotropy for high fluidity concrete. J Mater Civ Eng ASCE 2004;16(3): 247-56.

[15] Ferron RP, Gregori A, Sun Z, Shah SP. Rheological method to evaluate structural buildup in Self-consolidating concrete cement pastes. ACI Mater J 2007; 104:242-50.

[16] Assaad J, Khayat KH. Assessment of thixotropy of self-consolidating concrete and concrete-equivalent-mortar effect of binder composition and content. ACI Mater J 2004;101:400-9.

[17] Nehdi M, Al-Martini S. Coupled effects of high temperature, prolonged mixing time, and chemical admixtures on rheology of fresh concrete. ACI Mater J 2009;106:231-40.

[18] Lomboy GR, Wang X, Wang K. Rheological behavior and formwork pressure of SCC, SFSCC, and NC mixtures. Cem Concr Compos 2014;54:110-6.

[19] Mehdipour I, Razzaghi MS, Amini K, Shekarchi M. Effect of mineral admixtures on fluidity and stability of self-consolidating mortar subjected to prolonged mixing time. Constr Build Mater 2013;40:1029-37.

[20] Saleh Ahari R, Erdem TK, Ramyar K. Permeability properties of selfconsolidating concrete containing various supplementary cementitious materials. Constr Build Mater 2015;79:326-36.

[21] Rahman MK, Baluch MH, Malik MA. Thixotropic behavior of self compacting concrete with different mineral admixtures. Constr Build Mater 2014;50:710-7.

[22] Felekoglu B, Tosun K, Baradan B, Akin A, Uyulgan B. The effect of fly ash and limestone fillers on the viscosity and compressive strength of self-compacting repair mortars. Cem Concr Res 2006;36:1719-26.

[23] Vejmelkova E, Keppert M, Grzeszczyk S, Skalinski B, Cerny R. Properties of selfcompacting concrete mixtures containing metakaolin and blast furnace slag. Constr Build Mater 2011;25:1325-31.

[24] Erdem TK, Kirca Ö. Use of binary and ternary blends in high strength concrete. Constr Build Mater 2008:22:1477-83.

[25] Yuksel C, Saleh Ahari R, Abbaspoursani Ahari B, Ramyar K. Evaluation of three test methods for determining the alkali-silica reactivity of glass aggregate. Cem Concr Compos 2013;38:57-64.

[26] Ahmad S, Adekunle SK, Maslehuddin M, Azad AK. Properties of selfconsolidating concrete made utilizing alternative mineral fillers. Constr Build Mater 2014;68:268-76. 
[27] Sabet FA, Libre NA, Shekarchi M. Mechanical and durability properties of self consolidating high performance concrete incorporating natural zeolite, silica fume and fly ash. Constr Build Mater 2013;44:175-84.

[28] ASTM C494-08. Standard specification for chemical admixtures for concrete. ASTM International; 2008.

[29] Skarendahl A, Peterson SO. Self-compacting concrete. State of the art report of RILEM TC174-SCC, France, 2000. pp 47-55.

[30] Khayat KH, Bickley J, Lessard M. Performance of air-entrained, self consolidating concrete for casting basement and foundation walls. ACI Mater J 2000;97:374-80.

[31] ASTM C1611. Standard test method for slump flow of self-consolidating concrete. ASTM International; 2014.

[32] ASTM C39. Standard test method for compressive strength of cylindrical concrete specimens. ASTM International; 2012.

[33] Assaad J. Formwork pressure of self-consolidating concrete influence of thixotropy [Ph.D. thesis]. Sherbrooke: University of Sherbrooke; 2004.

[34] Lapasin R, Papo A, Rajgelj S. Flow behavior of fresh cement pastes. A comparison of different rheological instruments and techniques. Cem Concr Res 1983:3:349-56.

[35] ACI, Committee 237. 237R-07 self-consolidating concrete. 2007. p 30.

[36] Hassan A, Lachemi M, Hossain K. Effect of metakaolin and silica fume on rheology of self-consolidating concrete. ACI Mater J 2012;109:657-64.
[37] Caufin B, Papo A. The influence of the hydration process on the rheology of cement pastes. Zem Kalk Gips 1984;37:656-61.

[38] Tattersall GH. Workability and quality control of concrete. London: Chapman and Hall; 1991.

[39] $\mathrm{Hu} \mathrm{C}$, de Larrard F. The rheology of fresh high-performance concrete. Cem Concr Res 1996;26:283-94.

[40] Ferraris CF, de Larrard F. Modified slump test to measure rheologica parameters of fresh concrete. Cem Concr Aggre 1998;20:241-7.

[41] Roussel N, Ovarlez G, Garrault S, Brumaud C. The origins of thixotropy of fresh cement pastes. Cem Concr Res 2012;42:148-57.

[42] Tattersall GH, Banfill PFG. The rheology of fresh concrete. firs ed. London: Pitman Advanced Publishing Program; 1983.

[43] Struble LJ. The rheology of fresh cement paste. Conf Am Ceramic Soc $1991 ; 16: 7-29$

44] Roussel N. A thixotropy model for fresh fluid concretes: theory, validation and applications. Cem Concr Res 2006;36:1797-806.

[45] Omran AF, Khayat KH. Choice of thixotropic index to evaluate formwork pressure characteristics of self-consolidating concrete. Cem Concr Res 2014;63:89-97. 